\title{
N75 14384
}

THE RESPONSE OF SINGLE HUMAN CELLS TO ZERO GRAVITY

P. O'B. Montgomery, Jr., M.D.*; J. E. Cook, B.S.E.E.*;

R. C. Reynolds, M.D.†; J.S. Paul, Ph.D. *; L. Hayflick, Ph.D. ${ }^{\ddagger}$;

D. Stock, Ph.D.§; W. W. Schulz, Ph.D.*; S. Kimzey, Ph.D.**;

R. G. Thirolf, B.S.E.E.**; T. Rogers, Ph.D.**; D. Campbell, M.S.†; and $J$. Murrelzt.

\section{ABSTRACT}

The hardware, Woodlawn Wanderer 9, used to perform the S015 experiment, was fully automated and designed to achieve four major objectives.

- To maintain living cell cultures by supplying them with proper nutrients at a constant temperature of $36^{\circ} \mathrm{C}$,

- To produce two phase-contrast time-lapse motion pictures of living cells for 28 days,

- To fix a group of the cultures at predetermined intervals,

- To return some of the cultures of living cells intact for subsequent subculture and preservation.

These living cell cultures were maintained at a temperature of approximately $22^{\circ} \mathrm{C}$ after the first 12 days of the Skylab 3 mission.

The purpose of the 5015 experiment was to extend observations of the effects of zero gravity to include the study of some of these effects on living human cells during and after the 59-day Skylab 3 mission. A strain of diploid human embryonic lung cells, WI-38, was chosen for this purpose. The WI-38 cells were obtained from the laboratory of

\footnotetext{
*Laboratories for Cell Research, Woodlawn Hospital, Dallas County Hospital District, Dallas, Texas

tDepartment of Pathology, University of Texas, Southwestern Medical School, Dallas, Texas.

\#Department of Medical Microbiology, Stanford University, Palo Alto, California.

SUniversity of Texas, Health Science Section at Houston, M. D. Anderson Hospital, Houston, Texas.

**Cellular Analytical Laboratory, Johnson Space Center, Houston, Texas.
} 467 
Dr. Leonard Hayflick, Department of Medical Microbiology, Stanford University. The studies reported here were concerned with observations designed to detect the effects of zero gravity on cell growth rates and on cell structure using light microscopy, studies of cell function and cell cycle were performed using time-lapse motion picture photography, whereas studies for cell deoxyribonucleic acid content were performed using Feulgen staining and microspectrophotometry. Subsequent study of the returned living cells included karyotyping, G- and C-banding, and analyses of the culture media used. Some of the returned living cells were banked by deep-freeze techniques for possible future experiments.

The presentation of the experiment results will include a discussion of all these data in addition to the showing of a time-lapse motion picture of living human cells in the zero-gravity environment.

\section{INTRODUCTION}

The advent of satellites has awakened and renewed interest in the effects of gravity on living material. Prior to this time the major interest had been centered on the effects of increased gravity on living material as simulated by acceleration in various types of centrifuges. These studies began as early as 1806 when Knight used water driven centrifuges to demonstrate that it was the direction of the gravitational vector which oriented the growth of plants (1). In 1883 , E. Pflüger performed the classic experiment of maintaining a developing frog's egg in an inverted position and demonstrated that this led to abnormalities of development (2). In 1930, Harvey and Loomis working at Princeton, designed and constructed a centrifuge microscope (3). This instrument or modifications of it has been used to study the effects of acceleration on sea urchin eggs and amoebae $(4,5,6,7)$. Because of the buoyant effect of the media in which most specimens have been immersed during the period of acceleration, other investigators such as Matthews and Wunder have used a variety of terrestrial forms of life in their studies $(8,9)$. In general, as might be expected, it takes much larger increases in the gravitational field to produce detectable effects in bacteria (10) than it does to produce detectable effects in amoeba (11), and in the case of the more complex and heavier organisms from the size of rats to man, relatively small increments of gravity may produce measurable and/or lethal effects. 


\section{OBJECTIVES}

The purpose of the S015 experiment was to extend our observations of the effects of zero-gravity to living human cells during and subsequent to a 59-day flight on Skylab 3. A strain of diploid human embryonic lung cells, WI-38, was chosen for this purposel. The studies reported in this paper were concerned with observations designed to detect the effects of zero-gravity on cell growth rates and on cell structure as observed by light microscopy, transmission and scanning electron microscopy and histochemistry. Studies of the effects of zero-gravity on the cell function and the cell cycle were performed by time lapse motion picture photography and microspectrophotometry. Subsequent study of the returned living cells included karotyping, G- and C-banding, and analyses of the culture media used. Some of the living cells returned were banked by deep freeze techniques for possible future experiments.

Flight Hardware

The hardware, Woodlawn Wanderer 9, used to carry out the S015 experiment, was fully automated and designed to achieve four major objectives.

- To maintain living cell cultures by supplying them with proper nutrients and temperature, $36^{\circ} \mathrm{C}$.

- To produce two phase-contrast time-lapse motion pictures of living cells for 28 days.

- To fix a group of the cultures at predetermined intervals.

- To return intact some of the cultures of living cells for subsequent subculture and preservation. These cultures were maintained at approximately $22^{\circ} \mathrm{C}$ after the first 12 days of the mission.

As with most equipment developed for space flight, the hardware design was restricted by limitations of size, weight, and power while high reliability and safety standards were achieved. In this case, biological compatability of materials and the necessity to sterilize some of the components at high temperatures were major constraints not usually encountered in flight hardware design.

IWI-38 cel1s were obtained from the Laboratory of Dr. Leonard Hayflick, Department of Medical Microbiology, Stanford University. 
The hardware consisted of a single self-contained package installed in the spacecraft Command Module which supplied the power required to maintain an ambient temperature of between $10^{\circ}$ and $35^{\circ} \mathrm{C}$. The unit was hermetically sealed to provide an internal pressure of one atmosphere. Figure 1 is a photograph of the exterior of the unit. The fully loaded package weighed 10 kilograms and measured $40 \times 19 \times 17$ centimeters.

Internally, the package was separated into a camera-microscope section and a separately sealed growth curve experiment section. Figure 2 illustrates the interior arrangement with the camera-microscope section on top, the growth curve experiment section below, and the electronic circuitry required to fully automate the experiments located between the two.

In the camera-microscope section there were two independent cameramicroscope systems. One system photographed living cells through a 20 power phase-contrast microscope, the other photographed living cells through a 40 power phase-contrast microscope. Each microscope and lamp was miniaturized and measured $7 \times 4 \times 2.5$ centimeters. The phasecontrast image produced by the microscope was projected through an optical system onto the 16 millimeter film. The film was supplied by a film pack which contained two rolls of 16 millimeter film, each 100 meters 1ong. The camera which recorded through the 40 power microscope was operated for a 40 minute period once every 12 hours at the rate of five frames per minute. The 20 power microscope camera operated continuously and exposed one frame every 3.2 minutes.

Each camera-microscope system recorded the images of 1iving WI-38 cells grown on glass in a 0.05 cubic centimeter chamber. The chamber was formed by a gasket sandwiched between two glass discs. Tubes were attached to the gasket for the injection of fresh nutrient and for the removal of the waste medium. The entire chamber was held in a heated block thermostatically controlled to maintain a temperature of $36^{\circ} \mathrm{C}$.

In order to fill the chambers, culture medium containing $7000 \mathrm{cells} /$ milliliter was injected into the chamber through a syringe. After a few hours, the cells settled and became attached to the lower glass disc. The chamber was then installed in the microscope stage and the microscope was locked in a focused position.

Fresh medium was supplied by a cylindrical reservoir containing a piston threaded on a screw extending the length of the cylinder. After the screw was automatically rotated 4.5 revolutions every 12 hours, fresh medium was forced into the specimen chamber and waste medium was pulled into the vacuum created on the back side of the moving piston. 


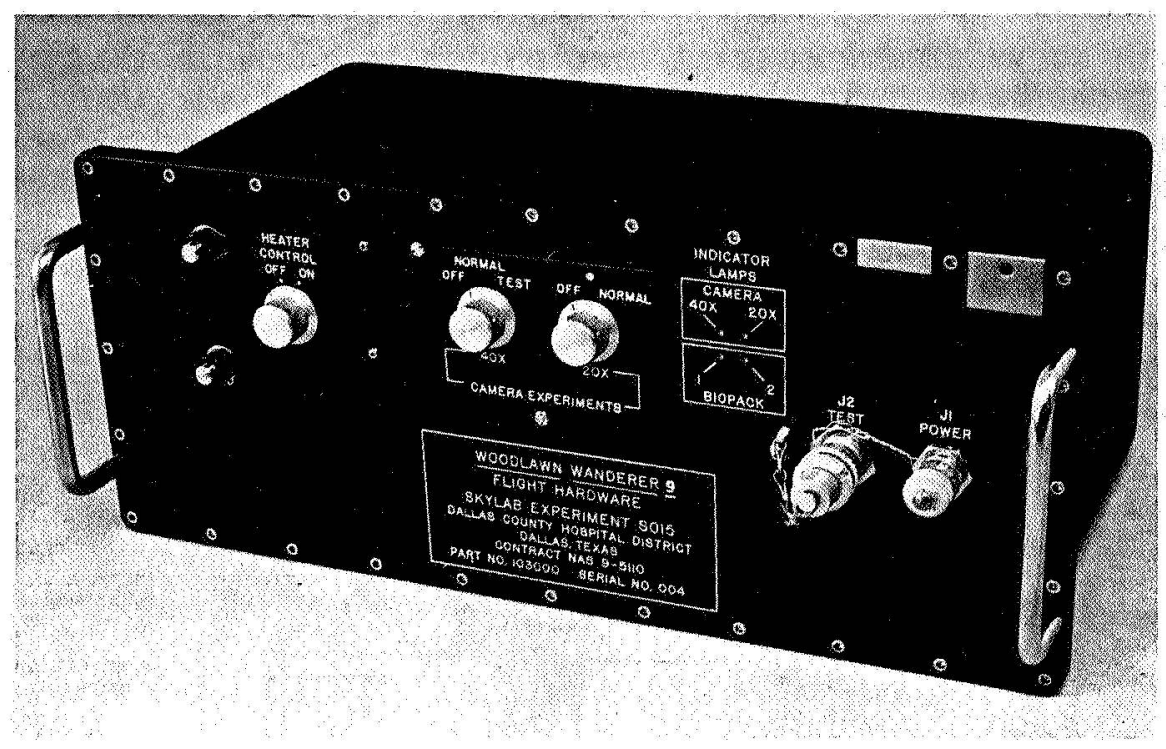

Figure 1. External configuration of Woodlawn Wanderer 9.

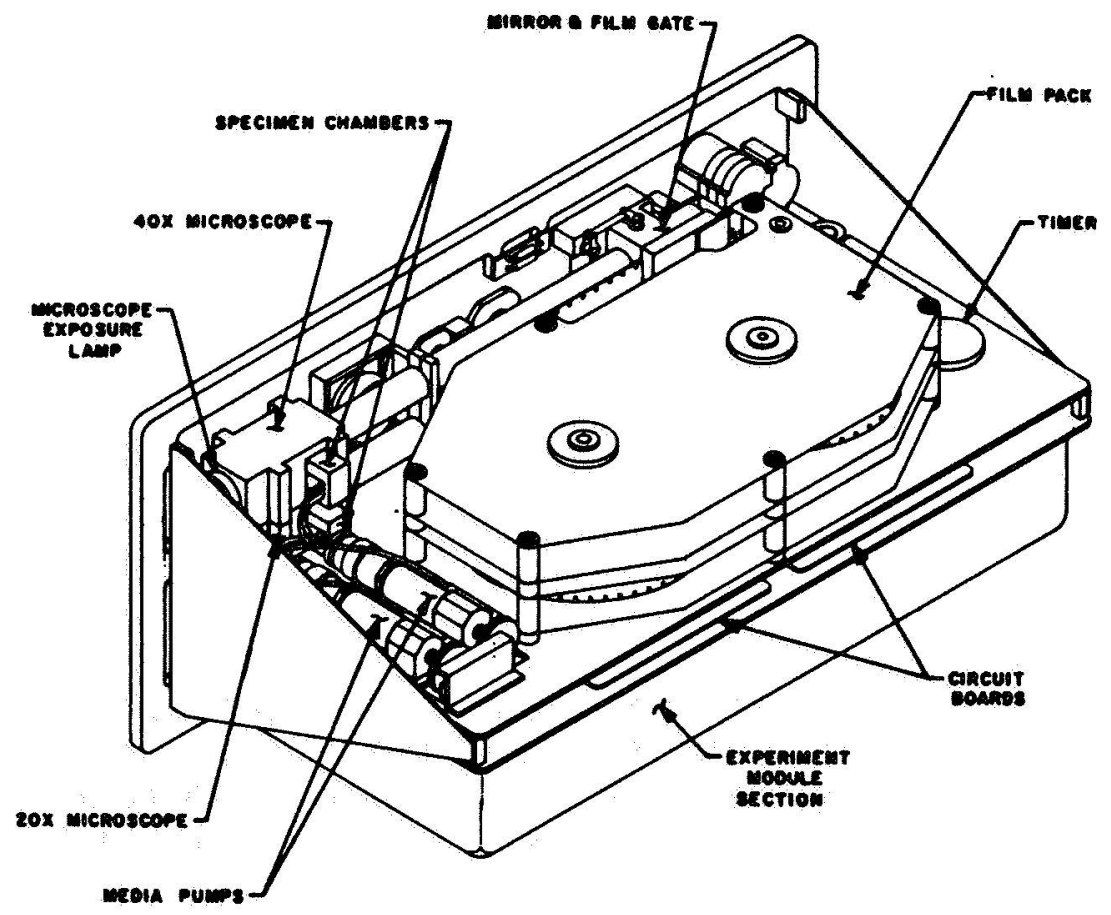

Figure 2. Interior configuration of Woodlawn Wanderer 9. 
The growth curve experiment was carried out in a module that was easily removed from the rest of the package for biological servicing. The module was separated into two identical independent assemblies to provide some degree of duplication and control (fig. 3). Each assembly

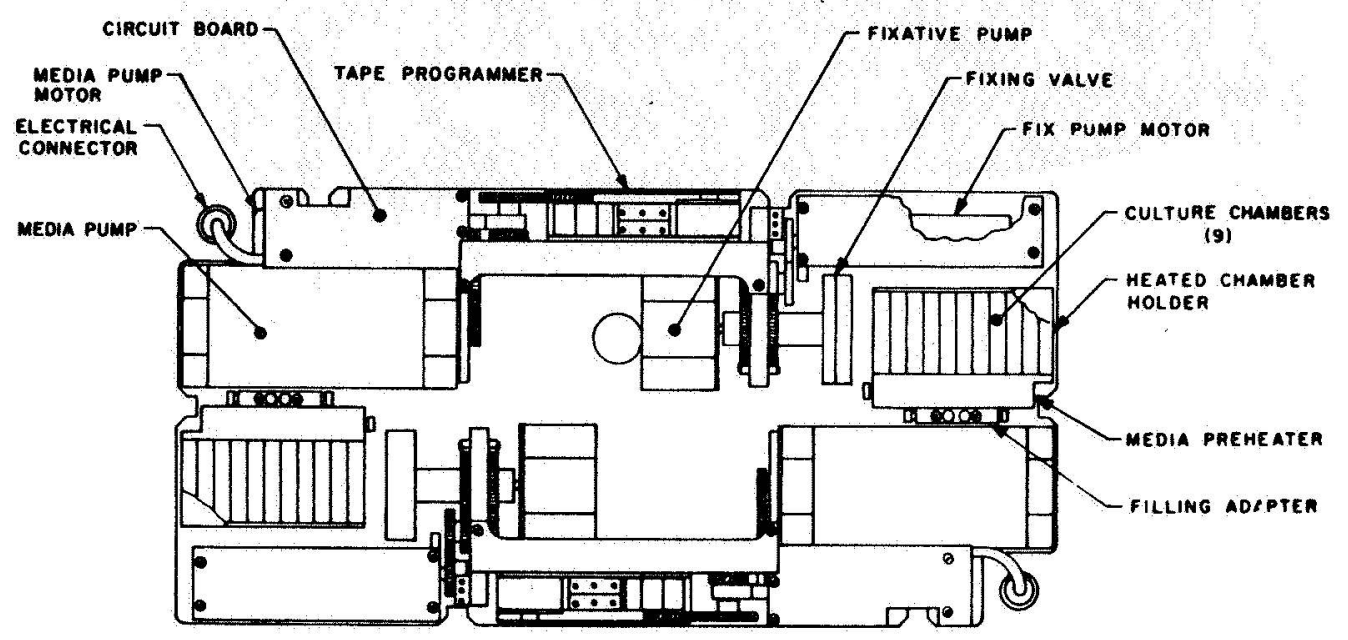

Figure 3. Interior of Woodlawn Wanderer 9.

provided nine miniaturized Rose-type cell culture chambers installed in a temperature-controlled holder. In each assembly the cells were fed automatically by a single nutrient medium pump-reservoir similar in design concept to those used in the camera-microscope systems. In this case, however, the medium passed through a reservoir to be heated before it was injected into the culture chambers in order to avoid temperature shock to the cells in the growth curve module. The culture chambers were connected by tubing in series such that the medium of the first chamber emptied into the second which emptied into the third and so on down the line. At each feeding enough medium was supplied to provide the last chamber in the series with fresh medium. 
At programed intervals during the experiment one chamber at a time was removed from the nutrient supply circuit and connected to a fixative supply by a device called the fixing valve. The fixative employed was 5 percent glutaraldehyde in Earle's Balanced Salt Solution. The fixing of cells was accomplished by a motor which, upon signal command by a mechanism using a programed punched tape, rotated the fixing valve 22.5 degrees and then advanced the fixative pump sufficiently to fill one chamber with fixative. Similar commands signaled by the program tape then effected fixation of the other chambers. Each time a culture was fixed it no longer required feeding and, accordingly, the tapeprogram signaled reduction of the amount of nutrient medium provided by the pump to the remaining culture chambers.

The program tape and nutrient supply pump were driven by the same motor. The tape was programed by two rows of punched holes. Microswitch actuators then rode on the tape and dropped into the holes to activate the motor. One row of holes controlled the release of the correct amount of each nutrient feeding while the other row initiated the cycles which injected the fixative solution into each chamber.

Four of the nine chambers of each assembly were not fixed in-flight and after mission day 12 were maintained at approximately $22^{\circ} \mathrm{C}$ with reduced feedings throughout the rest of the mission. These cells were returned live for subsequent subculturing.

\section{METHODS}

\section{Subcultivation and Ce11 Counting Procedures}

Stock cultures of mycoplasma free WI-38 cells, passage number 13, were trypsinized with 0.125 percent trypsin in phosphate buffered saline with 0.02 percent Versene. The cells were thoroughly agitated and suspended in Earle's BME ${ }^{2}$ buffered with 28 millimolar HEPES $^{3}$ and supplemented with 10 percent fetal calf serum and 100 units/ milliliter each of penicillin and streptomycin. The cells in this suspension were counted in a hemocytometer and then diluted to provide a final concentration of 1000 cells per square centimeter. This concentration of cells was then injected into the chambers and allowed to attach to the glass coverslips. After attachment of the cells, the cell population of each chamber was determined by counting the cells with the aid of phase-contrast microscopy. For

2BME = Eagle's basal medium Earle's.

${ }^{3}$ HEPES $=$ N-2-hydroxyethylpiperazine-N2-ethanesulfonic acid. 
this purpose a one millimeter grid reticle was placed in the 10X eyepiece of the microscope and only those cells were counted which had their nucleus inside or on the top and left edge of the grid square. A total of 16 such areas were counted by moving the chamber in a 4 by 4 pattern. After counting 16 areas, the average cell number per area and the $2 \sigma$ standard error were calculated. Areas outside of the $2 \sigma$ limits were rejected and a new average was calculated. This average was multiplied by a factor of 210 to give the number of cells per square centimeter in each chamber. Since there were no chambers fixed on day one, the average cell count of the five chambers was used as the point on the growth curve for day one.

When the hardware was returned to the laboratory after the flight, the cell population of each fixed chamber was again determined in the same manner as the initial cell count with one exception. When a population of 10000 cells per square centimeter was attained, counting was performed at a higher magnification by using the same grid reticle in a $15 \mathrm{X}$ eyepiece instead of the $10 \mathrm{X}$ eyepiece. This procedure was necessary to help eliminate the error in counting cells of high density population. The average number of cells per area was then multiplied by a factor of 400 to give the number of cells per square centimeter.

The final number of cells per square centimeter for each chamber was then plotted on 3-cycle semi-logrithmic paper corresponding to the day on which each particular chamber was fixed. For example, chamber 9-(GCM-1) plotted for day 3, chamber 9-(GCM-2) plotted for day 4 , chamber 8-(GCM-1) plotted for day 5, et cetera.

\section{Film Analys is Procedures}

The time lapse films were analyzed with a projector which permitted projection at 1-8, 16 and 24 frames/second in forward, reverse and sti11 and was equipped with a frame counter. Since the intervals between frames were known, it was possible to calculate the exact time of exposure of each frame.

Cells were counted on the projected image every three hours of recorded $20 \mathrm{X}$ film. When the cells reached confluency, counting became difficult because cells in close contact were not clearly distinguishable from each other. Consequently, further cell multiplication was determined by adding up the number of observed mitoses. For this purpose the time and location of every mitosis in the field were recorded.

Mitotic activity was calculated from the average cell density and the number of observed mitoses during a given time interval. 
The length of individual cell cycles was determined by projection of the $f i 1 \mathrm{~m}$ in reverse. Individual cells undergoing mitosis were followed to their previous mitosis or until they migrated out of the field or until they could not be clearly distinguished because they were in close contact with other cells. The observation in reverse was timesaving since only one cell needed to be followed instead of two as in the forward mode. This method also inherently excluded observation of cells which migrated out of the field in forward mode. The length of a cycle was arbitrarily chosen to be the time elapsed between the last frame of metaphase of one mitosis and the last frame of metaphase of the following mitosis.

The rate of cell migration was studied by covering the projection screen with paper and tracing the location of the nucleus of individual cells every hour. The displacements were then measured and tabulated. From these data average rates of migration were calculated for individual cells as well as for a given time interval.

\section{Transmission Electron Microscopy}

The whole coverslips with attached cell monolayers in 4 percent glutaraldehyde in a cacodylate buffer ${ }^{4}$ were received in the electron microscopy laboratory. The coverslips were scored with a diamond pencil and broken into four quarters. Three of the quarters were stored in 4 percent glutaraldehyde and used subsequently for scanning electron microscopy, phase microscopy, and microspectrophotometry. The remaining quarter was prepared for transmission electron microscopy.

The coverslips portions (quarters) for transmission electron microscopy were arranged in a specially designed Teflon rack and placed in an accompanying tank. The cells were rinsed for five minutes in distilled water and then postfixed in Palade's osmium tetroxide fixative (12) for 20 minutes. After a 5-minute distilled water rinse they were stained secondarily with 2 percent uranyl acetate in 70 percent ethyl alcohol for 20 minutes. Following staining with uranyl acetate the coverslips were dehydrated in graded alcohol solutions followed by two propylene oxide baths for five minutes each. The cells were then placed in a 1:1 mixture of propylene oxide and Maraglas for 30 minutes followed by straight Maraglas solution overnight, in the refrigerator. The following day the cells were allowed to come to room temperature. Beem plastic capsules were filled to within one-eighth inch of the top with Maraglas and the capsules as well as the coverslips were placed in a

${ }^{4}$ Cacodylate buffer is made as follows: glutaraldehyde 8 percent, EM grade, $100 \mathrm{cc} ; 0.2 \mathrm{M}$ sodium cacodylate, 84 milliliters; and 10X concentrated Earle's Balanced Salt Solution wi thout sodium bicarbonate, 16 milliliters; to make a total volume of 200 milliliters. 
bell jar which was evacuated to release any air bubbles which might be present in the Maraglas. After the vacuum treatment, the coversips were drained and laid cell side up on a thin piece of aluminum foil. The Beem capsules were inverted over the coverslips and the coverslips were then placed in a $60^{\circ} \mathrm{C}$ oven. After 16 to 17 hours and partial polymerization, the capsules were removed one at a time from the oven and, using a pair of tongs, the lower half of the coverslips was immersed in an acetone dry ice bath at $-80^{\circ} \mathrm{C}$ for about 60 seconds. The coverslip was immediately popped off using the thumb on part of the overlapping coverslip as leverage. This procedure was successful only if the capsules were taken from the oven one at a time since any cooling of the capsule resulted in failure of the coverslip to be removed. When the coverslip was removed, it left the monolayer of cells embedded in the Maraglas. The capsules were returned to the $60^{\circ} \mathrm{C}$ oven for 48 hours to complete polymerization. The Beem plastic capsule was cut and removed from the plastic block. The surface of the block containing the cell monolayer was then scored with a small radial saw producing one millimeter squares. The scored cell surface was examined under a dissecting microscope and an area selected for sectioning. The remaining squares were sawed off with a jeweler's blade and stored for future use. Sections were cut with a microtome and a diamond knife. Silver colored sections were used. Copper grids of 300 mesh with and without Formvar films were used to hold the sections. Sections were stained with uranyl acetate and lead citrate (13) and examined with a transmission electron microscope.

\section{Scanning Electron Microscopy}

Selected coverslip portions (quarters) with attached cell monolayers were prepared for scanning electron microscopy. The cells were fixed in glutaraldehyde and Palade's solution identical to the procedures outlined for transmission electron microscopy. They were dehydrated in graded alcohols and, after the absolute alcohol, they were transferred to a mixture of absolute ethanol and amyl acetate. This was followed by two changes of amyl acetate and subsequent critical-point drying, utilizing liquid carbon dioxide and a critical-point drying apparatus (14). After critical-point drying, the coverslips were removed from the drying chamber and coated with gold and palladium in an evaporator. The dried and coated specimens were examined with a scanning electron microscope.

\section{Phase Microscopy}

For phase microscopy the cells were fixed with glutaraldehyde and osmic acid as for electron microscopy. After osmic acid fixation the cells were rinsed in distilled water and mounted in a gelatin phenol mixture (15). The mixture of gelatin and phenol has a refractive index 
of approximately 1.041 and is an ideal embedding medium for examination of fixed cells with phase microscopy. The cells were examined with a regular phase and anoptral phase microscope utilizing a $W-58$ green filter. In addition, the preparations were studied with an interference phase microscope utilizing the $W-58$ green Wratten filter.

\section{Chromosome Analysis}

Chromosome analyses were performed on preflight and flight backup control cultures and on subcultured flight cultures. The cultures were incubated overnight with fresh growth medium, then harvested by standard colchimid arrest and hypotonic treatment procedures. Air dried slides were made for banding analysis. If the cultures were confluent when received they were lightly subcultured and harvested the following day. Cultures were saved and subsequently frozen for storage from a 11 lots of cells received. Air dried slides obtained from the cultures were treated with either urea (16) or trypsin (17) to obtain G-banding patterns. C-band patterns were obtained by the alkaline-SSC denaturation-renaturation procedure (18). All slides were coded before analysis and banding pattern data recorded by number to reduce bias. At least 50 cells were counted from each culture lot to determine the $2 n$ count. Five cells from each control culture were analyzed for G-band pattern and 10 cells were analyzed for C-band pattern. At least 10 cells of the "flight" culture were analyzed for G-band pattern and 20 cells were analyzed for C-band pattern.

\section{Microspectrophotometry}

Scanning microspectrophotometry was used to compare semiquantitative data from Feulgen-stained nuclei of human tissue culture cells grown during space flight (Skylab 3) in zero-gravity with matched ground controls $(19,20,21,22,23)$. In-flight and control specimens obtained on mission days $3,6,7,10$ and 11 were used for this study.

Scanning microspectrophotometry was performed on selected areas of the nuclei using a scanning microscope photometer having a 1-micron measuring spot at 1 micron intervals at 540 nanometers. For each nucleus scanned, three traverses through the center, or near the center, were made. The edited data provided a raw data matrix of $5 \times 3$ ( 15 adjacent optical density values 1 micron apart) from within the nucleus. The data was stored on LINC tape using a PDP-12 computer. Selected area scans of approximately 50 nuclei were obtained for each population of cells. Various computer programs were used for additional editing, raw data print-out matrices, and statistical analysis of the data. 
Tissue culture cells stained with Schiff's reagent using a modified Feulgen procedure were used for this study. To identify deoxyribonucleic acid (DNA) Schiff-positive sites in glutaraldehyde-fixed cells, it was necessary to modify the standard Feulgen reaction by addition of a prestaining oxidation with acidified hydrogen peroxide $\left(\mathrm{H}_{2} \mathrm{O}_{2}\right)$, a modification of procedure described by Pool (24).

Materials. Schiff's Reagent: Dissolve one gram of basic fuschin (Cert. PF-3, C.I. H2500) in 200 milliliters boiling distilled water. After cooling to $50^{\circ} \mathrm{C}$, filter and add $20 \mathrm{milliliters}$ of $1 \mathrm{~N}$ hydrochloric acid $(\mathrm{HCl})$ to the filtrate. Cool this solution to $25^{\circ} \mathrm{C}$, add 1 gram of sodium metabisulfite and place the solution in the dark for 24 hours. Decolorize with 2 grams of activated charcoal, and filter.

Oxidizing solution (HPSA): Prepare a 10 percent acidified hydrogen peroxide solution by adding 45 milliliters of 30 percent $\mathrm{H}_{2} \mathrm{O}_{2}$ to 90 milliliters of distilled water. Adjust the $\mathrm{pH}$ to 3.2 with $0.1 \mathrm{~N}$ sulfuric acid.

Procedure for processing tissue culture cells for DNA Schiff positive sites.

1. Oxidize with HPSA for 20 minutes.

2. Rinse briefly in distilled water.

3. Place in $1 \mathrm{~N} \mathrm{HCl}$ at $60^{\circ} \mathrm{C}$ for three minutes.

4. Rinse briefly in distilled water.

5. Transfer to Schiff's reagent for 30 minutes.

6. Rinse in distilled water.

7. Dehydrate in alcohol.

8. Clear in xylene and mount in Permount.

Media Analys is

When the flight hardware and the backup units were returned to the laboratory, samples of the used media were analyzed in the SMA-12 autoanalyzer at the clinical laboratories of Parkland Hospital in Dallas, Texas by Dr. Robert Putnam. Amino acid analyses were performed by Dr. Kenneth Wiggans, biochemist at the University of Texas Health Science Center in Dallas. These results were compared with similar analyses of freshly prepared media.

\section{RESULTS}

Growth Curve Analys is

Figure 4 delineates the data for the growth curves of the cells in the flight unit and for the cells in the second backup unit. Inspection of 
the two curves show them to be identical S-shaped growth curves. All of the ground based control studies performed yielded identical curves.
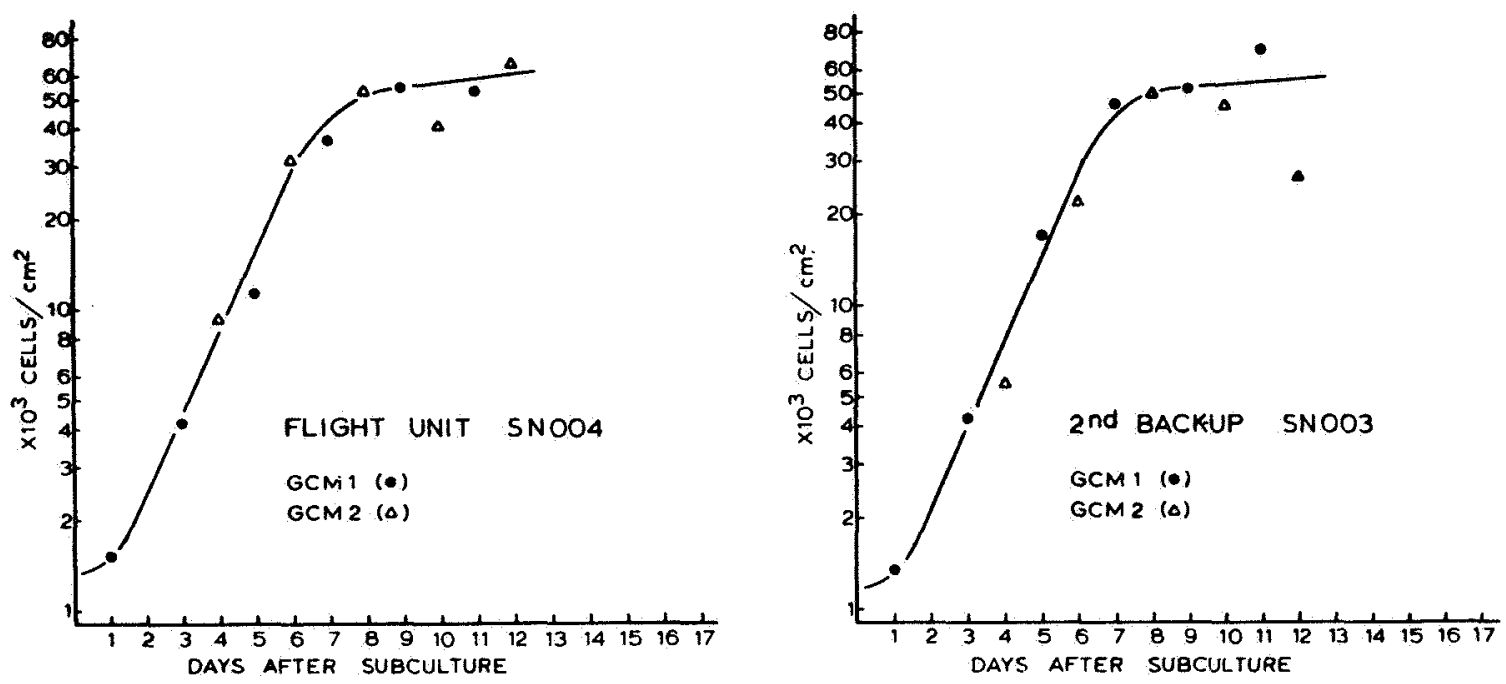

Figure 4. Growth curve data for flight and ground control units.

Film Analysis

Table I is a table of the length of individual cell cycles, in hours, from cells in the flight units and from cells in the backup units. The data indicate that exposure to zero-gravity did not influence the duration of the cell cycle nor the results of mitosis.

TABLE I. LENGTH OF INDIVIDUAL CELL CYCLES, IN HOURS

\begin{tabular}{cc} 
FLIGHT & CONTROL \\
\hline 28.2 & 32.4 \\
27.4 & 22.2 \\
23.7 & 20.8 \\
22.8 & 20.7 \\
22.5 & 19.6 \\
21.3 & 19.6 \\
21.0 & 18.8 \\
20.7 & 17.7 \\
19.9 & 17.2 \\
19.4 & 14.5 \\
18.5 & \\
\hline AVERAGE $22.3 \pm 3.1$ & $20.4 \pm 4.8$
\end{tabular}


Figure 5 is a graph indicating the number of mitoses in the flight units and in the backup units. As can be seen there are no significant differences between the flight units and the control or backup units.
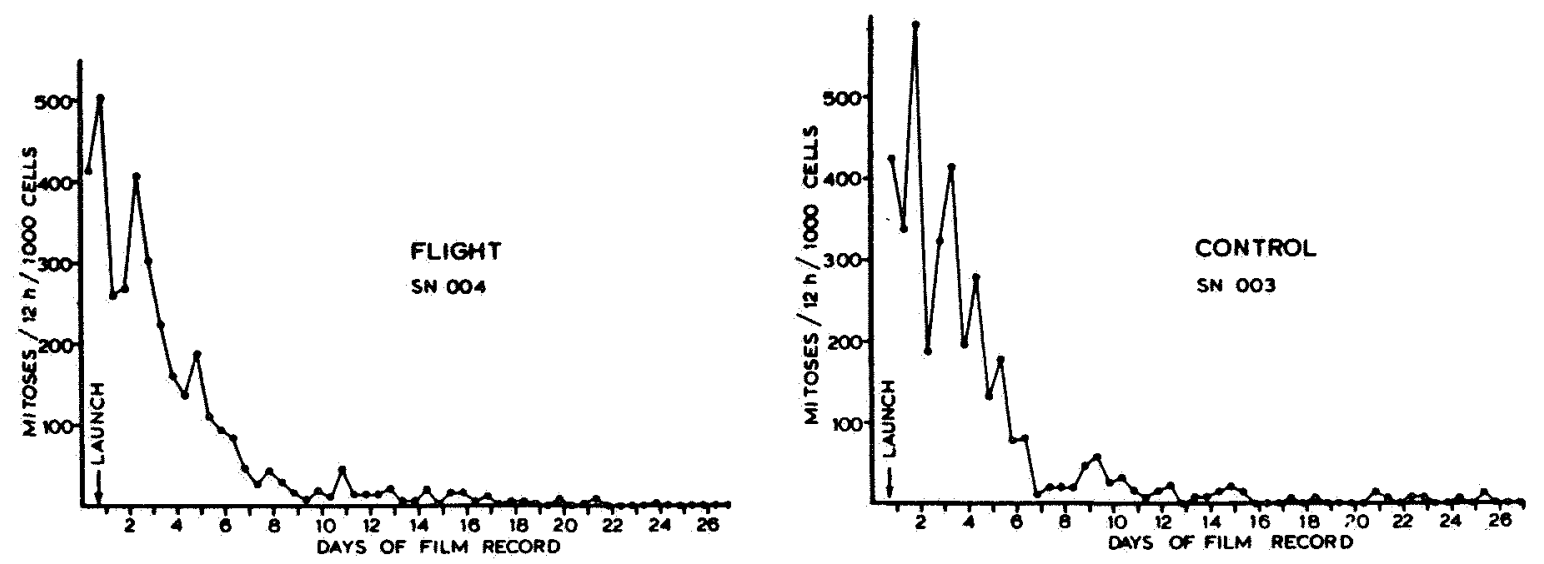

Figure 5. Mitotic Index for flight and ground control cuitures.

Table II compares the migration rates of cells in the flight unit with the migration of cells in the backup unit. In each case the migration rates are comparable.

TABLE II. RATES OF CELL MIGRATION IN THE FLIGHT AND GROUND CONTROL CULTURES

FLIGHT CONTROL

TOTAL NUMBER OF HOURLY DISPLACEMENTS MEASURED

$332 \quad 480$

AVERAGE RATE OF MIGRATION (microns/h)

$37.25 \quad 34.7$

STANDARD DEVIATION (microns/h)

$\pm 20.8 \quad \pm 22.5$

LOWEST OBSERVED RATE (microns/h)

3

0

HIGHEST OBSERVED RATE (microns/h)

95

114

The flight and control films were independently reviewed by several scientists. No differences between the flight films and the backup control films were observed for such cellular parameters as vacuole formation, mitosis, cell movement, cell size, nuclear size and location; 
nucleolar size, shape, location, and number; presence and location of cytoplasmic organelles, sol-gel state of the cytoplasm and cellular behavior on contact as confluence in each culture was reached.

\section{Chromosome Banding Pattern Analys is}

The normal G-band and C-bad patterns were found in all cultures, including the flight material, examined. No abnormalities of banding patterns were observed. The normal G-band pattern is presented in figure 6 and the normal C-band pattern is seen in figure 7 . Both figures are from the "flight" culture.

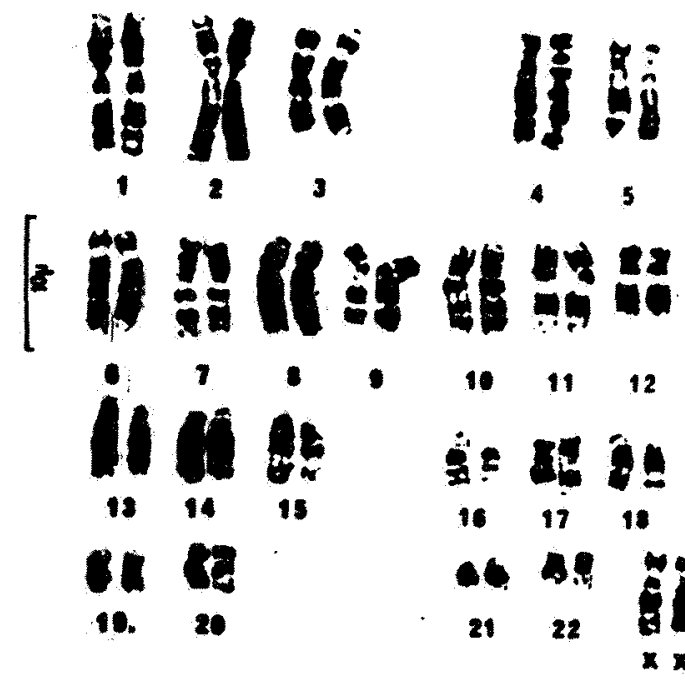

Figure 6. Chromosome G-banding of WI-38 flight cells.

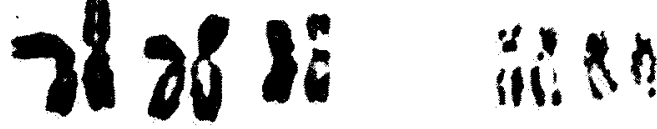

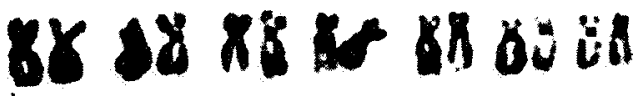
as is

ats in an

1. 10

Figure 7. Chromosome C-banding of WI-38 flight cells.

The preflight control culture received from Dr. Montgomery, the control and backup cultures. GCM-2053, GCM-2147, GCM-2138, GCM-1808, and the "flight" culture GCM-2052 received from the Hayflick Laboratory all grew well and all were normal diploid lines.

C-banding patterns (constitutive heterochromatin) are known to vary greatly in human populations (25) while G-band patterns are extremely stable. The G-band pattern of man may even be recognized as changed little from those in other nigher primates $(26,27)$. Therefore, we 
expected that rearrangements in flight material, if found, would be of the C-band type. However, no C-band changes were noted in any of the cultures.

The results obtained from this study are in keeping with data accumulated by this laboratory from a number of experiments with both human and nonhuman cell cultures. It has been established that diploid cultures, properly maintained, seldom show rearrangements of the chromosomes or changes in banding patterns (28). Cells subjected to radiation (29), chemical stress (30) or other stiress factors (31) may develop chromosomal abberations.

\section{Microspectrophotometry}

The average optical density value for the 15 determinations from each nucleus was obtained. This value was then used to obtain a mean and \pm 1 standard deviation (SD) for each population. The results are shown in Table III.

TABLE III. AVERAGE OPTICAL DENSITY OF NUCLEI OF FLIGHT (F)

AND CONTROL (C) CELLS

\begin{tabular}{|c|c|c|c|c|c|c|c|c|c|c|}
\hline & \multicolumn{2}{|c|}{ 3-DAY } & \multicolumn{2}{|c|}{ 6-DAY } & \multicolumn{2}{|c|}{ 7-DAY } & \multicolumn{2}{|c|}{ 10-DAY } & \multicolumn{2}{|c|}{ 11-DAY } \\
\hline & C & $\mathbf{F}$ & C & $F$ & C & F & C & F & C & $\mathbf{F}$ \\
\hline Mean & 40 & 44 & 39 & 48 & 41 & 40 & 46 & 45 & 45 & 40 \\
\hline $\pm 1 S D$ & 14 & 15 & 12 & 12 & 13 & 12 & 12 & 11 & 11 & 7 \\
\hline
\end{tabular}

The mean for in-flight specimens is within \pm 1 SD of the corresponding control. The decrease in the standard deviation with increase in age of the cells is attributed to cell culture growth characteristics. The three-day specimens were characterized by a low population density and the cells were in an asynchronous growth state with all stages of the cell cycle represented. 
Figure 8 is a histogram of the frequency of occurrence of the average nuclear optical density value for 3-day, 6-day, 7-day, 10-day, and 11-day control and in-flight nuclei. The distribution of the values shows nuclei in $\mathrm{GT}, \mathrm{S}$ and $\mathrm{G} 2$ phases.
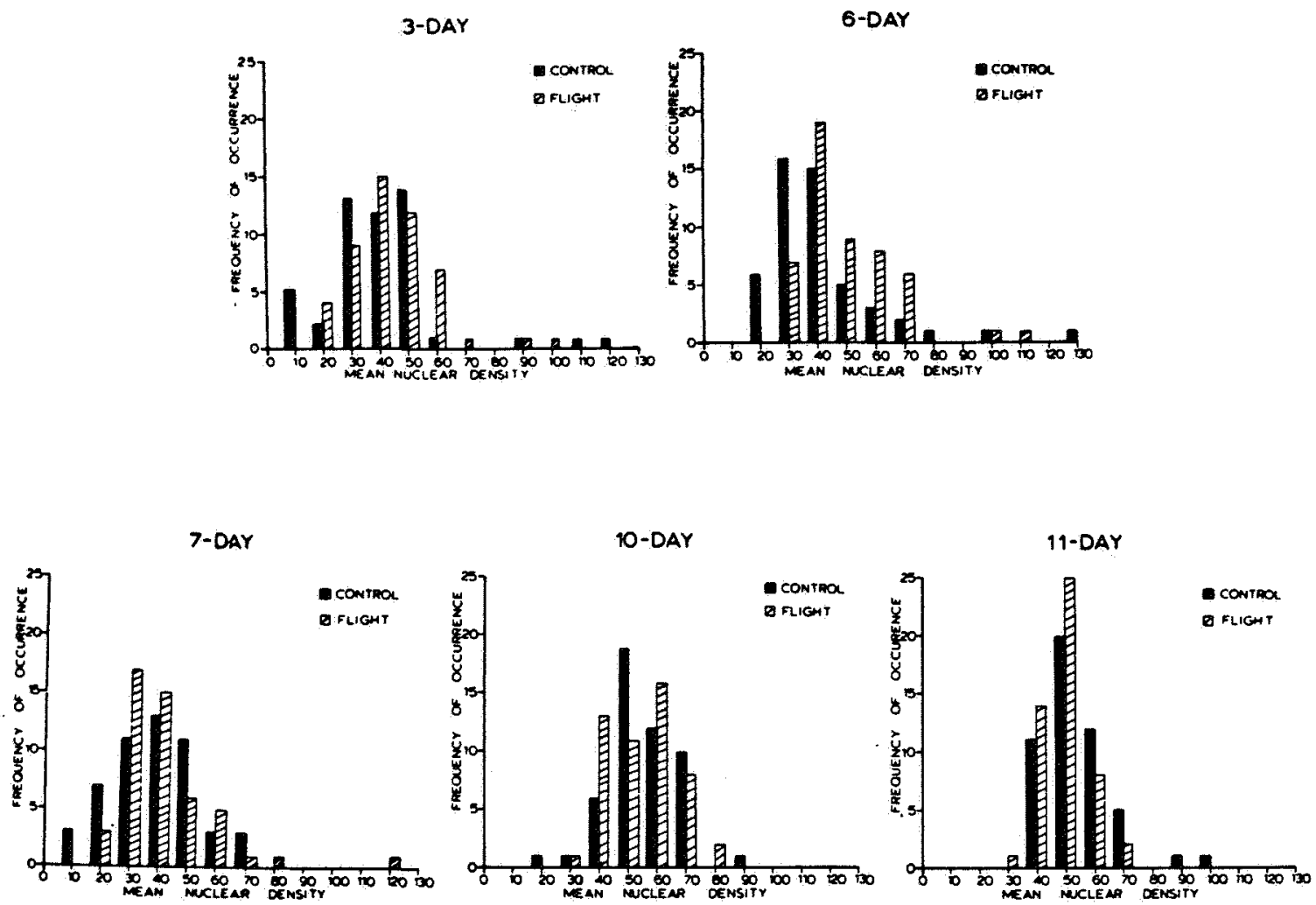

Figure 8. Histogram showing average optical density of flight and control cells.

The 11-day nuclei exhibit a much narrower range in distribution and were also characterized by the lowest standard deviation. This is attributed to the cells having reached a stationary phase since the optical density values indicated a rather uniform population of nuclei in the GI phase. When the histograms of the populations are compared, the trend from a growth phase (3- and 6-day) to a stationary phase (10- and 11-day) is readily observed.

Whenever possible, mitotic nuclei were scanned in the 3-, 6- and 7-day specimens. On the basis of optical density values, it was determined that all mitotic nuclei contained the $2 \mathrm{C}$ complement of nucleoprotein. 
None of the scanned yielded data suggesting aneuploidy at the $4 \mathrm{C}$ or $8 \mathrm{C}$ level. Mitotic nuclei in the 10-day and 11-day specimens were rarely seen and when found, they were usually not in a position to obtain accurate data.

\section{Medium Analysis}

Table IV is the result of the SMA-12 analysis of the freshly prepared medium, the used flight medium and the used medium irom the backup control unit. The freshly prepared medium differs from the two used medium samples mainly in a higher glucose concentration. There is an unexplained difference in glucose concentration in the used control culture medium (75 $\mathrm{mg} \%$ ) and the flight culture medium (93 $\mathrm{mg} \%$ ). Otherwise, there is no significant difference between the used flight medium and the used control medium.

TABLE IV. SMA-12 ANALYSIS OF FRESH, USED FLIGHT, AND USED GROUND CONTROL CULTURE MEDIUM

\begin{tabular}{|c|c|c|c|c|c|}
\hline & FRESH MEDIA & FLIG & UNIT & $\mathrm{COI}$ & TROL \\
\hline & & GCM1 & GCM2 & GCMI & GCM2 \\
\hline $\mathrm{Na}^{+}(\mathrm{meq} / 1)$ & 130.0 & 131.0 & 132.0 & 131.0 & 130.0 \\
\hline $\mathrm{K}^{+}($meq $/ 1)$ & 5.98 & 6.22 & 6.24 & 6.24 & 6.20 \\
\hline $\mathrm{CO}_{2}(\mathrm{meq} / 1)$ & 3.2 & 0.9 & 1.2 & 1.0 & 1.0 \\
\hline T.P. $(g \%)$ & 0.7 & 0.3 & 0.35 & 0.3 & 0.3 \\
\hline Alb. (g\%) & 0.22 & 0.06 & 0.01 & 0.08 & 0.08 \\
\hline $\mathrm{Ca}^{++}(\mathrm{mg} \%)$ & 7.3 & 7.35 & 7.35 & 7.32 & 7.35 \\
\hline Glu. (mg\%) & 124.0 & 94.0 & 91.0 & 71.0 & 79.0 \\
\hline BUN (mg\%) & 2.0 & 1.0 & 1.0 & 1.0 & 1.0 \\
\hline Creat. (mg\%) & 0.55 & 0.39 & 0.42 & 0.4 & 0.4 \\
\hline Alk. Phos. (mU/ml) & 32.0 & 9.0 & 29.0 & 28.0 & 28.0 \\
\hline SGOT $(\mathrm{mJ} / \mathrm{ml})$ & 14.0 & 6.0 & 7.0 & 6.0 & 6.0 \\
\hline
\end{tabular}

Table $V$ gives the results of the amino acid analyses for the freshly prepared medium, the used flight medium and the used backup control unit medium. There appear to be no significant differences between the two samples of used medium. 
TABLE V. AMINO ACID ANALYSIS OF FRESH, USED FLIGHT, AND USED GROUND CONTROL CULTURE MEDIA

\begin{tabular}{lccccc} 
& FRESH MEDIA & \multicolumn{2}{c}{ FLIGHT UNIT } & \multicolumn{2}{c}{ CONTROL } \\
& & GCM 1 & GCM 2 & GCM 1 & GCM 2 \\
\hline LYSINE & 0.0405 & 0.0527 & 0.0502 & 0.0471 & 0.0391 \\
IIISTIDINE & .0092 & .009 & .0088 & .0085 & Trace \\
ARGININE & .0113 & Trace & Trace & Trace & \\
ASPARTIC ACID & .0057 & .0049 & .0033 & .0062 & .0060 \\
THREONINE & .0318 & .0318 & .0326 & .0251 & .0280 \\
SERINE & .2825 & .280 & .277 & .222 & .266 \\
GLUTAMIC ACID & .0537 & .0447 & .0442 & .0493 & .0527 \\
GLYCINE & .0122 & .0150 & .0197 & .0135 & .0137 \\
ALANINE & .0160 & .0288 & .0376 & .0283 & .0315 \\
CYSTINE (HALF) & .0034 & & & & \\
VALINE & .0379 & .0360 & .0344 & .0298 & .033 \\
METHIONINE & .0328 & .0153 & .0106 & .0121 & .0085 \\
ISOLEUCINE & .0501 & .0282 & .0301 & .0260 & .0280 \\
LUECINE & .104 & .0305 & .0326 & .0283 & .0328 \\
TYROSINE & & .0137 & .0154 & .0134 & .0124 \\
PIIENYLALANINE & & .0151 & .0171 & .0146 & .007
\end{tabular}

Phase, Electron, and Scanning Microscopy of Fixed Cells

A zero-gravity environment produced no observable differences in the flight cells as compared with the ground controls. Both flight and control cells showed identical morphologic changes during the period of the experiment, which we have attributed to age and population density of the cuitures. These changes are similar to aging changes in WI-38 cells described by Lipetz and Cristofalo (32). Microvilli are relatively sparse as compared with those present in other cell lines such as Chang liver and Hela cells. As the culture ages and a complete monolayer is formed, the cells become spindle shape and are aligned in a longitudinal direction with other cells to form unidirectional bundles. As these bundles of cells, grow and increase in size, they intersect other bundles at varying angles. At the point of junction the two bundles of cells not only interlace but may cross each other at different levels forming a multiple cell layer, rather than a monolayer of cells.

Young cultures at 3 to 6 days of age are rich in ribosomes, filamentous mitochondria, and endoplasmic reticulum, especially in the central portions of the cytoplasm corresponding to the endoplasm. The outer 
ectoplasm is rich in microtubules and microfibrils (fia. y) microfibrils are especially dense adjacent to the plasma membrane where they form distinct bundles which may be demonstrated as light or dark bands with phase microscopy. These bands run in a longitudinal direction just beneath the plasma membrane of the cell (fig. 10).

As the cultures age, a variety of cytoplasmic vacuoles are formed. Transmission electron microscopy shows the vacuoles may be dilated mitochondria, lysosomes, and autophagosomes and fat vacuoles

(Fig. 10).

In the 11 to 12 day old cultures filamentous mitochondria and $7 y$ sosomes are decreased. Endoplasmic reticulum may be decreased and there appears to be a piling up of ribosomes around slightly dilated endoplasmic reticulum tubules. There is a marked increase in the number of microtubules and microfibrils (fig. 11).

Scanning electron microscopy confirms the phase microscopy and transmission electron microscopy, observations that these cells have a generally smooth surface and relatively few microvilli. Movies reveal rapid membranous movement of the distal cell surfaces in a beating fashion. This activity was demonstrated in static fashion with the scanning electron microscope (figs. 12 and 13).

\section{CONCLUSION}

Twenty separate cultures of WI-38 human embryonic lung cells have been exposed to a zero-gravity environment on a space satellite for periods of time varying from one to 59 days. Duplicate cultures were run concurrently as ground controls. Ten cultures were fixed during the first 12 days of flight. Growth curves, DNA microspectrophometry, phase microscopy, and ultrastructural studies of the fixed cells revealed no effects of a zero-gravity environment on the ten cultures.

Two cultures were photographed by means of phase time-lapse cinematography during the first 27 days of the flight. Analysis of the films revealed no differences in mitotic index, cell cycle, and migration between the flight and control cells.

Eight cultures were not fixed but returned to earth in a viable state after being incubated at $36^{\circ} \mathrm{C}$ during the first 12 days of the flight and at $22^{\circ} \mathrm{C}$ for the remainder of the flight. At the present time only karotyping and chromosome banding have been performed in these cells. There are no differences between the flight and control cell cultures.

Minor unexplained differences have been found in biochemical constituents 


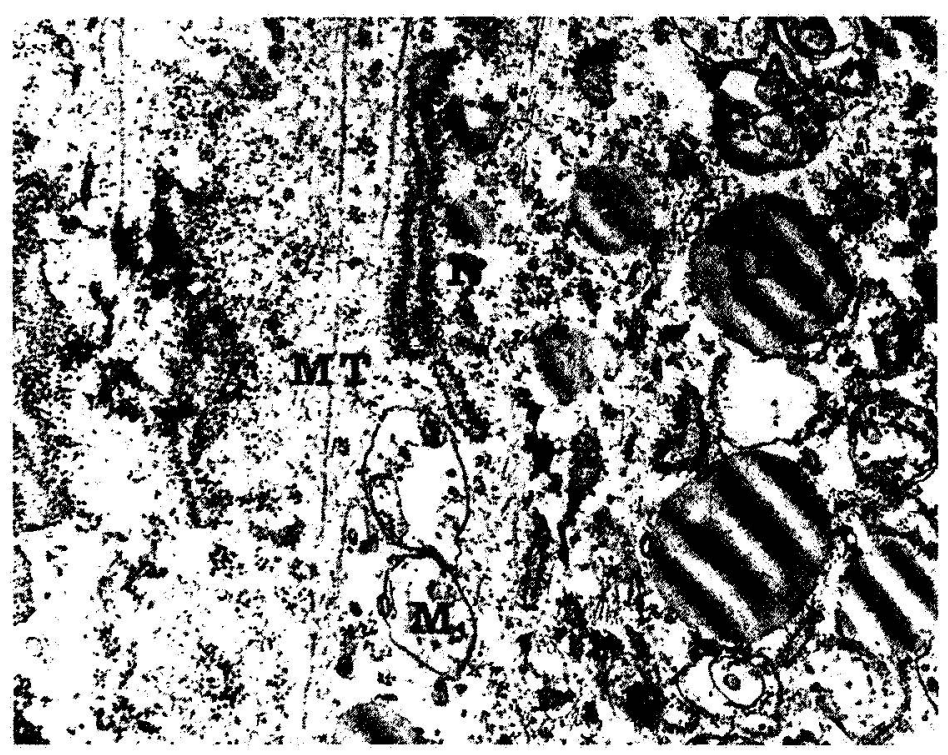

Figure 9. Transmission electron photomicropraph of 6-day old culture at junction of central organelle rich zone of cytoplasm and ectoplasm. Vacuoles in central zone represent swollen mitochondria (M), lysosomes, microtubules (MT), autophagosomes (A) and lipid droplets (L). Endoplasmic reticulum (R). Flight and control cultures are identical. Magnification 50 000X.

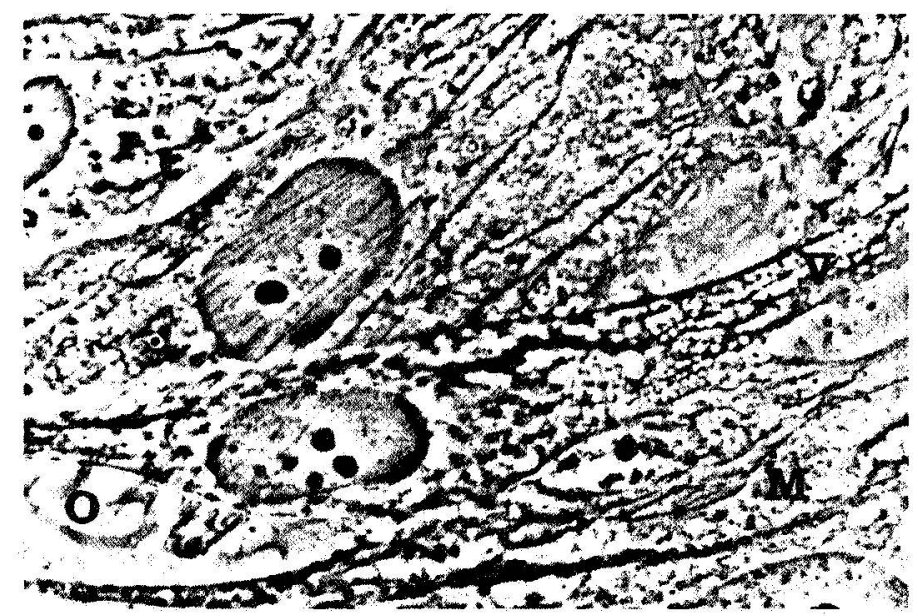

Figure 10. Phase photomicrograph of 8-day old WI-38 cell culture. Note overgrowth of one cell over another producing a multilayered colony $(0)$. Numerous clear vacuoles are present $(V)$. A few filamentous mitochondria (M) are present. Glutaraldehyde and osmium tetroxide fixation. Gelatin-phenol mount. Magnification 2000x. 


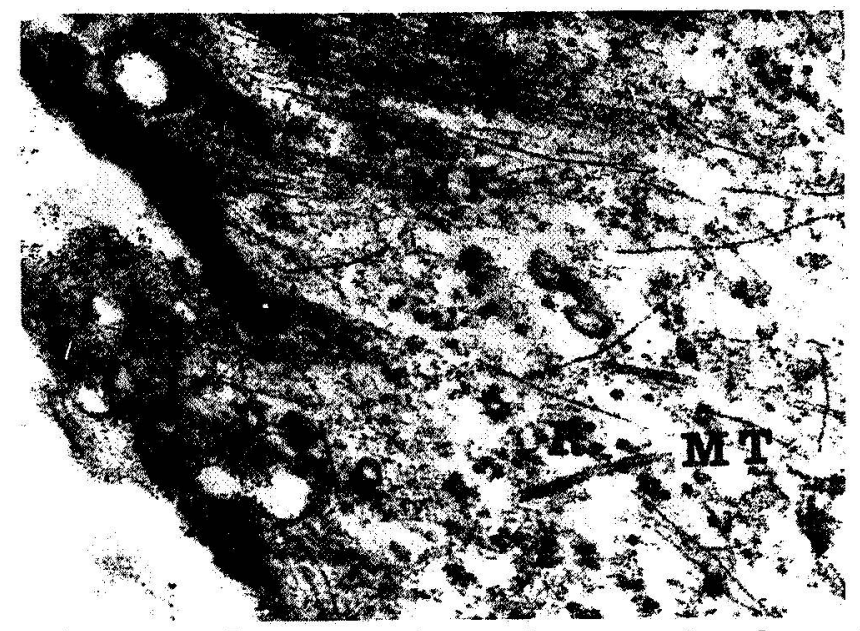

Figure 11. Transmission electron photomicrograph of peripheral cytoplasm showing free ribosomes (R), microtubules (MT) and bundles of microfibrils (MF) beneath plasma membrane. Magnification 100 000X.

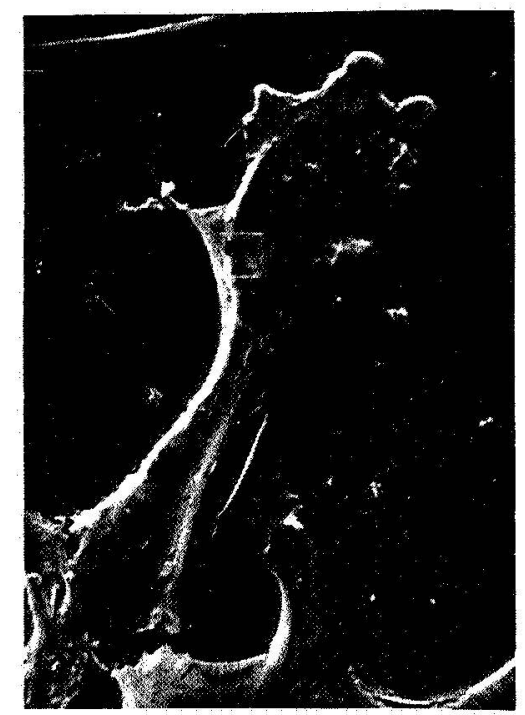

Figure 12. Scanning electron photomicrograph of WI-38 cell near end of telophase. Some cytoplasmic bubbling (B) is present. Triangular shaped membranous cytoplasm is beginning to form (T).

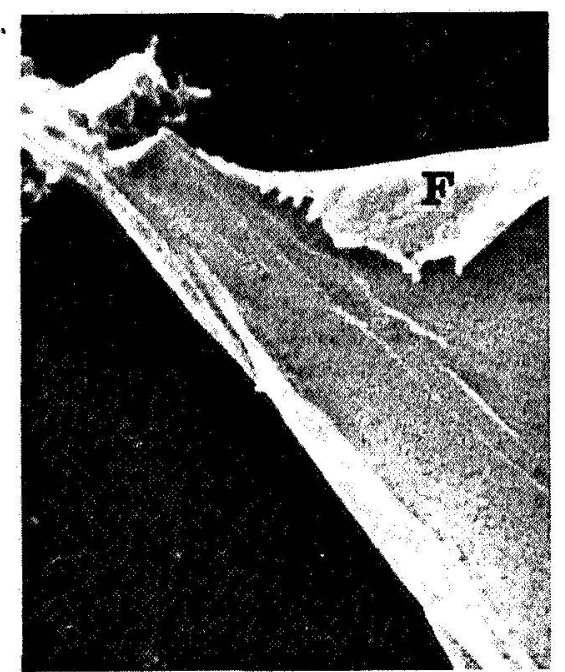

Figure 13. High magnification of trianguiar shaped membranous cytoplasm in previous picture. Note folded cytoplasm (F), static view of the membranous beating of peripheral cytoplasm typical of cells in tissue culture. Microvilli are sparse in the WI-38 cell. Magnification $20000 x$. 
of the used flight and control media. Our present opinion is that these changes are of no significance.

Within the limits of the experimental design, it was found that a zerogravity environment produced no detectable effects on Wistar-38 numan embryonic lung cells in tissue culture.

\section{REFERENCES}

1. Knight, Thomas A. 1806. On the Direction of the Radical and Germen during the Vegetation of Seeds. Phil. Trans. Royal Soc. London, Vol. 96, pp. 99-108.

2. Pflüger, Eduard F. W. 1883. Uber den Einfluss der Schwerkraft auf die Theilung der Zellen. Axchiv fur die Gesarmte Physiologie des Menschen und der Thiere, vol. 31, pp. 311-318.

3. Harvey, E. N. and A. L. Loomis. 1930. Scientific Apparatus and Laboratory Methods: A Microscope Centrifuge. Science, vol. 72 , no. 1854 , pp. $42-44$.

4. Allen, R. D. 1960. The Consistency of Ameba Cytoplasm and Its Bearing on the Mechanism of Ameboid Movement. II. The Effects of Centrifugal Acceleration Observed in the Centrifuge Microscope. J. Biophys. Biochemistry Cytology, vol. 8, pp. 379-397.

5. Allen, R. D. and J. D. Roslansky. 1959. The Consistency of Ameba Cytoplasm and Its Bearing on the Mechanism of Ameboid Movement. I. An Analysis of Endoplasmic Velocity Profiles of Chaos Chaos (1). J. Biophys. Biochemistry Cytology, vol. 6, pp. 437-446.

6. Harvey, E. N. and D. A. Marsland. 1932. The Tension at the Surface of Amoeba dubia with Direct Observations on the Movement of Cyotplasmic Particles at High Centrifugal Speeds. J. CeZZ Comp. Phys., vol. 2, pp. 75-97.

7. Heilbrunn, L. V. and K. Daugherty. 1932. The Action of Sodium, Potassium, Calcium and Magnesium Ions on the Plasmagel of Amoeba proteus. Physiology Zoology, vol. 5, pp. 254-274.

8. Matthews, B. H. C. Proceedings of the Physiological Society, July 24-25, 1953. Adaptation to Centrifugal Acceleration. J. of Physiol., vol. 122, p. 31.

9. Wunder, C. C. 1962. Survival and Growth of Organisms during Life-Long Exposure to High Gravity. Aerospace Med., vol. 33, pp. 355-356. 
10. Montgomery, P. O'B., F. Van Orden and E. Rosenblum. 1963. A Relationship Between Growth and Gravity in Bacteria, Aexospace Med., vol. 34, no. 4, pp. 352-354.

11. Montgomery, P. O'B., J. Cook and R. Frantz. 1965. The Effects of Prolonged Centrifugation on Amoeba proteus. Exp. Cell Res., vol. 40 , pp. 140-142.

12. Palade, G. E. 1952. A Study of Fixation for Electron Microscopy. J. Exp. Med., vol. 95, pp. 285-298.

13. Reynolds, Edward S. April 1963. The Use of Lead Citrate at High $\mathrm{pH}$ as an Electron Opaque Stain in Electron Microscopy. J. of cell Biol., vol. 13, pp. 208-212.

14. Anderson, T. E. 1951. Techniques for the Preservation of 3-Dimensional Structure in Preparing Specimens for the Electron Microscope. Trans. N. Y. Acad. Sci., II, vol, 13, p. 130.

15. Dixon, R. Phillippine and J. H. Holmes. October 1962. Teaching Slide Preparations of Urinary Sediment. Amer. J. of Clin. Path., vol. 38 , no. 4 , pp. 444-448.

16. Shiraishi, Y. and T. H. Yosida. 1972. Banding Pattern Analys is of Human Chromosomes by Use of a Urea Treatment Technique. Chromosoma (Ber1.), vol. 37, pp. 75-83.

17. Seabright, M. 1972. The Use of Proteolytic Enzymes for the Mapping of Structural Rearrangements in the Chromosomes of Man. Chromosoma (Berl.), vol. 36, pp. 204-210.

18. Stefos, K. and F. E. Arrighi. 1971. Heterochromatic Nature of W Chromosome in Birds. Exptt. Cell Res., vol. 68, pp. 228-231.

19. Bartels, P. H., G. F. Bahr, J. Griep, H. Rappaport and G. L. Wied. 1969. Computer Analyses of Lymphocytes in Transformation. A Methodologic Study. Acta Cytol., vol. 13, pp. 557-568.

20. Barte1s, P. H., G. F. Bahr and G. L. Wied. 1970. Information Theoretical Approach to Cell Identification by Computer. In Automated Cell Identification and Cell Sorting, G. L. Wied and F. G. Bahr eds., Academic Press, New York, pp. 361-384.

21. Rogers, T. D., V. E. Scholes and H. E. Schlichting, Jr. 1972. Rapid Scanning Microspectrophotometry of Colorless Euglena grucizlis and Astoria Zonga. A Basis for Differentiation. J. Protozool., vol. 19, pp. 150-155. 
22. Wied, G. L., P. H. Bartels, G. F. Bahr, and D. C. 01dfield. 1968. Taxonomic Intra-Cellular Analytic System (TICAS) for Ce11

Identification. Acta Cytol., vol. 12, pp. 180-204.

23. Wied, G. L., G. F. Bahr and P. H. Barte1s. 1970. Automated Analysis of Cell Images by TICAS. In Automated Cell Identification and Cell sorting, G. L. Wied and G. F. Bahr eds., pp. 195-360.

24. Pool, Charlotte R. 1973. Prestaining Oxidation by Acidified $\mathrm{H}_{2} \mathrm{O}_{2}$ for Revealing Schiff-Positive Sites in Epon-Embedded Sections. Stain Technology, vol. 48, no. 3, pp. 123-126.

25. Craig-Holmes, A. P. and M. W. Shaw. 1971. Polymorphism of Human Constitutive Heterochromatin. Science, no. 174, pp. 702-704.

26. De Grouchy, J., and C. Turleau. 1972. Evolution Caryotypiques de 1 'homme et du Chimpanze. Etude Comparative des Topographies de Bands Apres Denaturation Menagee. Ann. Genet., vol. 15, pp. $79-84$.

27. Stock, A. D., and T. C. Hsu. 1973. Evolutionary Conservatism in Arrangement of Genetic Material: A Comparative Analys is of Chromosome Banding Between the Rhesus Macaque ( $2 n=42,84$ arms) and the African Green Monkey $(2 n=60,120$ arms). Chromosoma (Ber1.), vo1. 43, pp. 211-224.

28. Hsu, T. C. and J. E. K. Cooper. (in press), 1974. On Diploid Cell Lines. J. Natl. Cancer Inst.

29. Fox, M. and A. H. Nias. 1968. The Assessment of Radiation and Chemical Damage in Cultured Mammalian Cells. J. Physioz., vol. 197, pp. 52-53.

30. Bartalos, M. and T. A. Baramki. 1967. Effects of Drugs on Chromosomes. In Medical Cytogenetics, The Williams and Wilkins Company, Baltimore, pp. 400-404.

31. Hampe1, K. E. and A. Levan. 1964. Breakage in Human Chromosomes Induced by Low Temperature. Hereditas, vo1. 51, pp. 315-343.

32. Kipetz, J. and V. J. Cristofa10. 1972. U1trastructural Changes Accompanying the Aging of Human Diploid Cells in Culture. J. UZtrastructure Res., vol. 39, pp. 43-56. 